\title{
Temperature and Rainfall Thresholds corresponding to water consumption in Greater Melbourne, Australia
}

\author{
$\underline{\text { R.C. Sarker }}^{\text {a }}$, S. Gato-Trinidad ${ }^{\mathrm{b}}$ and M. Imteaz ${ }^{\mathrm{c}}$ \\ ${ }^{a}$ PhD Candidate, Faculty of Engineering and Industrial Sciences, Swinburne University of Technology, \\ Australia \\ ${ }^{b}$ Lecturer, Faculty of Engineering and Industrial Sciences, Swinburne University of Technology, Australia \\ ${ }^{c}$ Senior Lecturer, Faculty of Engineering and Industrial Sciences, Swinburne University of Technology, \\ Australia \\ Email: rcsarker@swin.edu.au
}

\begin{abstract}
Water demand modelling is a crucial issue in the current climate of water restrictions and water conservation in Melbourne, Australia. Average annual inflows into Melbourne's major reservoirs since 1913 dropped rapidly by almost 40\% during the 1997-2009 (Millennium Drought). This led to the development of the Sustainable Water Strategy for Central Region by the Victorian Government. The Strategy identified wide range of actions to secure water supplies in Victoria's Central Region for the next 50 years. The Strategy also sets a per capita consumption reduction target of $25 \%$ from 1990's average use by 2015, increasing to $30 \%$ by 2020. Water conservation efforts and initiatives were and are being implemented with interest in quantifying the impact of water conservation programs on reducing water demand. However, evaluation of the effectiveness of these options requires considerable effort since each of these options has a distinguishing set of environmental, social and economic outcomes. There has been significant modelling made to date to incorporate the effects of water conservation programs, although these are still in the early stage of development.
\end{abstract}

Basic water demand models are based on the premise that total water use is made up of base use and seasonal use with base use characterised by the water use during winter. Previous models described base use to be mainly indoor use that is weather insensitive, however, a number of studies revealed that base use is weather dependent and water usage during winter months may include garden watering in some areas. In some cases, base use was modelled as representative of winter usage, based on the months of lowest usage in a year, but correlation of base use values with temperature and rainfall was not undertaken for residential water use. Even correlation of base use values with temperature and rainfall is still not undertaken for mixed water uses comprising of residential (indoor use), industrial, and commercial. In this context, there is still a need to investigate whether base use for water demand modeling is weather-insensitive or weather-sensitive. Hence, threshold of temperature and rainfall needs to be determined to investigate whether "base use" values which are mainly for indoor purposes are weather insensitive or whether "base use" values represent winter usage that may include gardening in other areas or cities i.e. weather sensitive and not mainly indoor use.

This paper determines the thresholds at which water consumption is independent of temperature and rainfall. In general, when surface air temperature increases, consumption of water increases and when rainfall increases, water consumption decreases. However, a threshold point is reached beyond which increase of temperature and rainfall values no longer result to increase or decrease in water consumption. In one word, beyond the threshold line water use is independent of temperature and rainfall. To fulfil the aim of this research, daily water consumption of Greater Melbourne from Melbourne Water and daily temperature and rainfall data recorded by Bureau of Meteorology, Australia from January 01, 1980 to December 31, 2009 are analysed.

From the analysis, temperature threshold is found as $15.53{ }^{\circ} \mathrm{C}$ for Greater Melbourne while rainfall threshold as $4.08 \mathrm{~mm}$. It could be noted that at temperature higher than $15.53{ }^{\circ} \mathrm{C}$, daily water use increases as the temperature increases but below this threshold, daily water use seemed to be independent of temperature and increases in water use at this level could be attributed to population increase or other factors. The identified temperature threshold accounts for 23 percentile of the daily maximum temperature recorded from January 1980 to December 2009 and usually occurred during the months of May-September. Daily water use increases as the rainfall decreases but above this threshold of $4.08 \mathrm{~mm}$, any more rainfall would no longer contribute to daily water use reduction. This could be due to the resulting saturated soil moisture content or water use has already been driven to its base use level. The identified rainfall threshold accounts for 70 percentile of the daily rainfall recorded from January 1980 to December 2009.

Keywords: Temperature and rainfall thresholds, Water consumption, Water demand model 


\section{INTRODUCTION}

Population growth, climate change and limited water resources emphasized by the current drought are placing enormous pressure on traditional sources of water supply. As water plays a crucial role in the location, function, and growth of communities (Marshall, 1879), conflicts over water have always involved competition among alternative uses or among geographical regions, and water has become the source of increasing controversy, as supplies fail to meet demand in many areas (Arbues et al, 2003). The effective application of water is essential in geographical regions where the demand is increasing due to the growing population or an improved living standard and is reaching the limit of the fresh water resources (Jacobs, 2002). Australia is such a region and water demand management (WDM) is increasingly relevant. However, Australia is moving towards more sustainable urban water cycle management with rapid advances in the use of recycled water, rainwater, stormwater and demand management as alternatives to the use of traditional water supply augmentation approaches.

Water demand modelling is an important issue in the current climate of water restrictions and water conservation in Melbourne, Australia. The Victorian Government developed the Sustainable Water Strategy for Central Region which identified wide range of actions to secure water supplies in Victoria's Central Region for the next 50 years. The Strategy sets a per capita consumption reduction target of 25\% from 1990's average use by 2015 , increasing to $30 \%$ by 2020 . By this way and trend, water conservation efforts and initiatives were and are being implemented with interest in quantifying the impact of water conservation programs on reducing water demand. Hence, alternative supply and demand management options have been employed and more other options can be employed. However, evaluation of the effectiveness of these options requires considerable effort since each of these options has a distinguishing set of environmental, social and economic outcomes. There has been significant modelling made in some areas, although modelling efforts are in the early stages of development.

Basic demand models are based on the premise that total water use can be divided into two parts e.g. base use and seasonal use (Zhou et al., 2002), where base use is characterised by the water use during winter months and seasonal use dependent on seasonal, climatic and persistence components (Taylor, 2012). Previous models described base use to be mainly indoor use that is weather insensitive (Maidment et al., 1985; Zhou et al., 2000) however, a number of studies revealed that base use is weather dependent and water usage during winter months may include garden watering in some areas (Gibbs, 1978; Miaou, 1987; Gato et al., 2003). In some cases, base use was modelled as representative of winter usage, based on the months of lowest usage in a year, but correlation of base use values with temperature and rainfall was not undertaken (Maidment et al., 1985; Zhou et al., 2000). For water demand modelling An et al. (1995) considered weather factors and water consumptions (Herrera et al., 2010) while the main climatic influences have been identified as rainfall and temperature, together with investigations of humidity (Aly \& Wanakule, 2004) and evapo-transpiration (Campbell et al. 2004). Gato et al (2007) raised the issues:

- Can base use values be assumed as weather-insensitive and mainly for indoor use?

- Do base use values represent winter usage that may include gardening in other areas or cities i.e. weather-sensitive and not mainly indoor purposes?

Gato et al (2007) also concluded that a base use model representing mainly indoor water use and is based on identified reference that means threshold of temperature and rainfall needs to be developed. Miaou (1990) and Arbues et al (2003) also stated the importance of investigating the thresholds beyond which precipitation or temperature no longer affect water use.

Gato et al (2007) found that incorporating threshold levels of $15.27^{\circ} \mathrm{C}$ and $4.82 \mathrm{~mm}$ temperature and rainfall improved daily water demand model significantly for East Doncaster, Australia from $\mathrm{R}^{2}$ of $65 \%$ to $80 \%$.

While previous water demand models correlate base use values with temperature and rainfall mostly for residential areas, threshold levels and water demand model incorporating these levels are still to be undertaken for cities or areas with mixed uses of water (e.g. residential, industrial, commercial).

This paper identifies the threshold levels in temperature and rainfall for Greater Melbourne, Australia that can be useful for water demand modelling in areas with mixed uses of water.

\section{BRIEF REVIEW OF DEMAND MODELLING}

Forecasting urban water demand has been considered on an annual or monthly basis in previous papers and only few addressed daily water use. In addition, past papers recognised the importance of incorporating threshold levels in temperature and rainfall but only few have identified them or incorporate them in water demand modelling. While a number of water demand models developed for purely residential areas incorporate 
threshold levels, there is still a need to identify and incorporate these levels in areas which are not purely residential (residential, commercial and industrial).

Maidment et al. (1985) developed a short-term forecasting model based on Box and Jenkins (1976) time series analysis. The formulation of their model rests on the following three assumptions:

1. total urban water use can be divided into base use, which is weather-insensitive and observed as average use in the winter months, and seasonal use, which is weather-sensitive and observed as the difference between base use and total use during the other months of the year;

2. in the absence of rainfall, seasonal use follows a characteristics pattern over the year that is dependent on temperature conditions; and

3. the occurrence of rainfall causes an immediate drop in seasonal use that gradually diminishes over time.

Many factors are connected with the water demand behaviour (Herrera et al., 2010) that means the demand function can be estimated using variables that reflect outside characteristics (Arbues et al., 2003), such as irrigable area per dwelling unit (Howe and Linaweaver, 1967), garden size (Nieswiadomy and Molina, 1989; Lyman, 1992; Hewitt and Hanemann, 1995), sprinkler system (Lyman, 1992), or pool ownership (Dandy et al., 1997). Temperature is the more relevant because it directly influences multiple sources of water consumption such as showers, cooling systems and gardens. But water consumers respond better to the occurrence of rainfall and other climate variables (An et al., 1995). For water demand modelling An et al. (1995) considered weather factors and water consumptions (Herrera et al., 2010) while the main climatic influences have been identified as rainfall and temperature, together with investigations of humidity (Aly \& Wanakule, 2004) and evapotranspiration (Campbell et al. 2004; Taylor, 2012). Many variables have been utilised in models to account for the impact of climate on water use. Temperature and precipitation are two of the most common, and possibly the most effective, meteorological variables (Zhou et al., 2002). Morgan and Smolen (1976) found these two variables most significant when compared with potential evapotranspiration minus precipitation and monthly binary seasonal variables in a cross-sectional study for 33 cities in Southern California (Zhou et al., 2002). Regarding this connection, Maidment and Miaou (1986) applied the model to daily water use data from nine cities, three each from Florida, Pennsylvania, and Texas. They reported that in Austin, Texas, a spatially averaged rainfall series showed a clearer relationship with water use than rainfall series from a single gauge. There was a non-linear response of water use to air temperature changes. That's why, they are critical about the linearity between water demand and weather variables. They suggest that rainfall has a dynamic effect in the sense that it reduces water demand initially, but the effect diminishes over time. Its effect is also statedependent, the higher the water uses before a rainfall, the stronger the effect (Miaou, 1990). Nonlinearities are of concern to many authors (Herrera et al., 2010; Arbues et al., 2003; Gato et al., 2007).

Zhou et al. (2000) also adopted the methodology based on time series analysis in which daily water consumption is considered to be the sum of base consumption and seasonal consumption, the latter comprising of seasonal, climatic and persistence components. Using the daily water use from Melbourne, Australia a time series model was formulated as a set of equations to forecast daily urban water demand. These equations represent the effects of four factors namely trend, seasonality, climatic correlation and autocorrelation on water use. The annual trend in base consumption was represented by a polynomial as a function of time. Seasonal water use was modelled by seasonal, climatic and persistence components in consideration of the summer and winter six months separately. The response of water use to rainfall depended first on the occurrence of rainfall and second on its magnitude (Zhou et al, 2000).

Both of these models considered base use as weather independent and is represented by a polynomial as a function of time. However, in modelling seasonal use, Maidment and Miaou (1986) employed a nonlinear heat function relating water use to air temperature during rainless period to deseasonalise the series and relied on just two climatic variables, rainfall and temperature while Zhou et al. (2000) used a Fourier series to estimate the seasonal cycle in water use and in addition to the two variables included Class A pan evaporation, Antecedent Precipitation Index (API) and the number of days since previous rainfall.

Gato et al. (2003) also adopted the methodology based on a simple time series analysis in which daily water consumption is considered to be the sum of base consumption and seasonal consumption. Using the daily demand for East Doncaster, Victoria, Australia water supply distribution zone, which is mostly residential a simple linear regression analysis to forecast short-term water use is also adopted. The day of the week, temperature and rainfall were found to be statistically significant in the base use equation developed. Seasonal water use was modelled as comprising of potential water use and short memory effects of climatic factors. 


\section{STUDY AREA AND DATASET}

Study area in this work covers Greater Melbourne. In-situ dataset of total daily water consumption (ML/D), daily maximum temperature $\left({ }^{\circ} \mathrm{C}\right)$ and daily rainfall $(\mathrm{mm})$ collected from January 01, 1980 to December 31, 2009 are considered for this study. Total daily water consumption dataset of Greater Melbourne water supply distribution zone are collected from Melbourne Water. Temperature and rainfall daily dataset are recorded at Melbourne Regional Office by Bureau of Meteorology, Australia (Station number: 086071).

\section{METHODOLOGY}

\subsection{Determination of temperature threshold}

To identify the temperature threshold level, the total daily water use was regressed against daily maximum temperature. Analysis of the resulting regression equation of daily water use and daily maximum temperature suggests that data transformation of water use $\left(\mathrm{W}_{\mathrm{d}}\right)$ needs to be adopted. In this case a reciprocal function of water consumption was used (Devore, 1991; Gato et al, 2007). Then a polynomial function of the reciprocal of the corresponding daily water use, $\left(1 / \mathrm{W}_{\mathrm{d}}\right)$ was fitted against daily maximum temperature, $\left(\mathrm{T}_{\mathrm{d}}\right)($ Figure $\mathbf{1})$. The resulting equation is:

$\mathrm{T}_{\mathrm{d}}=21.64\left(1 / \mathrm{W}_{\mathrm{d}}\right)^{3}-33.96\left(1 / \mathrm{W}_{\mathrm{d}}\right)^{2}-11.99\left(1 / \mathrm{W}_{\mathrm{d}}\right)+41.43$

Where $\mathrm{T}_{\mathrm{d}}=$ daily maximum temperature $\left({ }^{\circ} \mathrm{C}\right)$, and $\mathrm{W}_{\mathrm{d}}$, =total daily water consumption (ML/Day). Taking derivatives of equation (1) and setting the derivatives to zero, the temperature threshold is obtained as

$\mathrm{T}_{\mathrm{Td}}=15.53^{\circ} \mathrm{C}$

A quadratic function of the reciprocal of the corresponding daily water use, $\left(1 / \mathrm{W}_{\mathrm{d}}\right)$ was also tried to fit against daily maximum temperature, $\left(T_{d}\right)$, however, the polynomial function showed a better fit in showing the threshold level than the quadratic function (Figure 1).

\subsection{Determination of rainfall threshold}

The approach adopted to identify rainfall threshold is similar to identifying temperature threshold without data transformation. The polynomial (quadratic) function of daily water use, $\mathrm{W}_{\mathrm{d}}$ is fitted against daily rainfall, $\mathrm{R}_{\mathrm{d}}$ on days when rain occurs (Figure 2). The resulting equation is:

$\mathrm{R}_{\mathrm{d}}=-3 \mathrm{E}-06\left(\mathrm{~W}_{\mathrm{d}}\right)^{2}+0.007 \mathrm{~W}_{\mathrm{d}}$

Where $\mathrm{R}_{\mathrm{d}}=$ daily rainfall $(\mathrm{mm})$, and $\mathrm{W}_{\mathrm{d}}=$ total daily water consumption (ML/Day). Taking derivatives of that equation (2) and setting the derivatives to zero, rainfall threshold is obtained as

$\mathrm{R}_{\mathrm{Td}}=4.08 \mathrm{~mm}$

A polynomial function of daily water use, $\left(\mathrm{W}_{\mathrm{d}}\right)$ was also tried to fit against daily rainfall, $\left(\mathrm{R}_{\mathrm{d}}\right)$ as undertaken for temperature, however the quadratic function of $\mathrm{W}_{\mathrm{d}}$ suits better than that of polynomial function.

\section{RESULT AND DISCUSSION}

The analysis shows that the temperature threshold is $15.53{ }^{\circ} \mathrm{C}$ for greater Melbourne. It could be noted that at temperature higher than $15.53{ }^{\circ} \mathrm{C}$, daily water use increases as the temperature increases but below this threshold, daily water use seemed to be independent of temperature and increases in water use at this level could be attributed to population increase or other factors. The identified temperature threshold accounts for 22.87 percentile of the daily maximum temperature recorded from January 1981 to December 2009 and usually occurred during the months of May-September.

Daily water use increases as the rainfall decreases but above this threshold of $4.08 \mathrm{~mm}$, any more rainfall would no longer contribute to daily water use reduction. This could be due to the resulting saturated soil moisture content or water use has already been driven to its base use level. The identified rainfall threshold accounts for 70.40 percentile of the daily rainfall recorded from January 1980 to December 2009. 


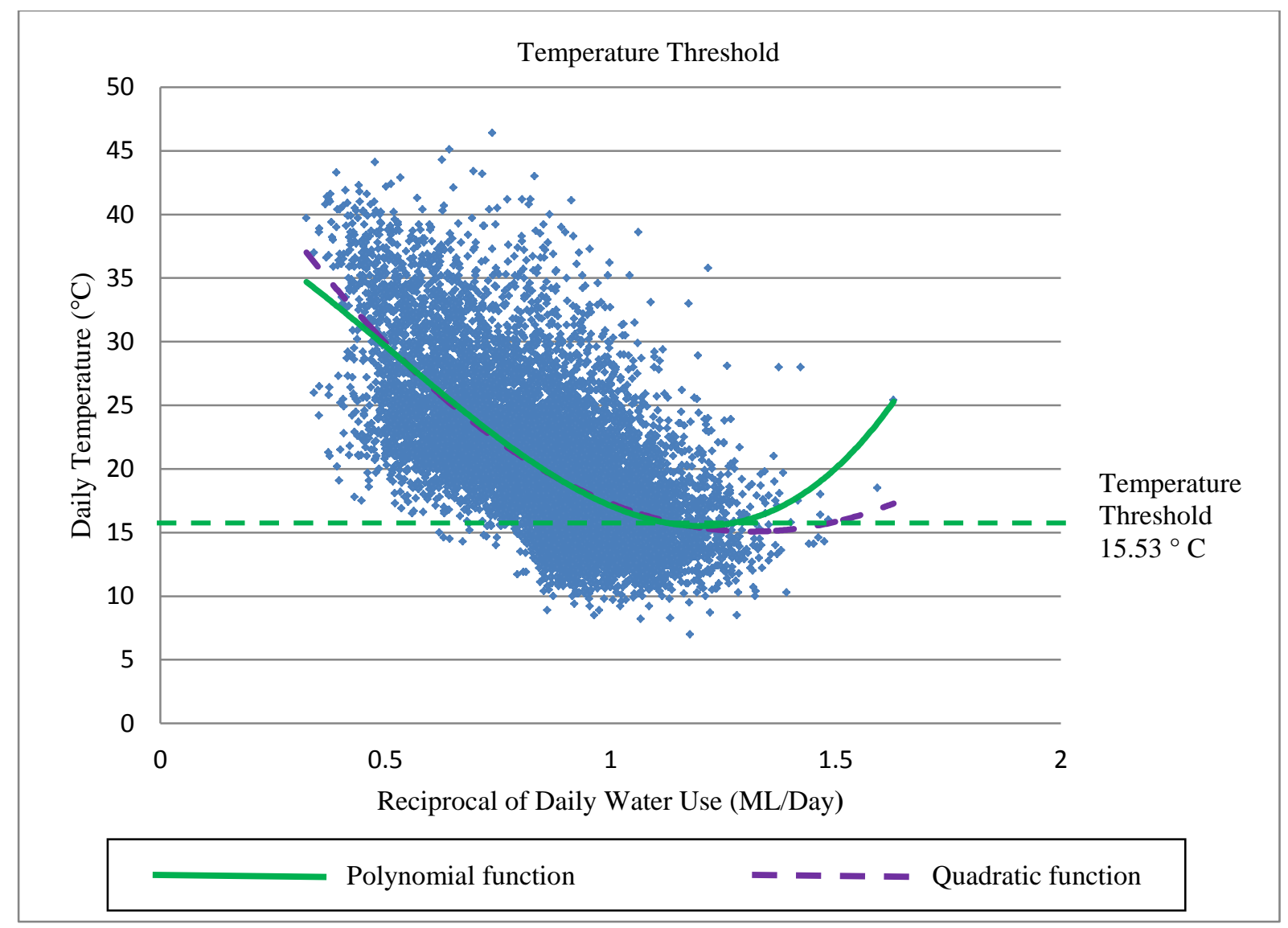

Figure 1. Determination of temperature thresholds corresponding to water consumption in greater Melbourne.

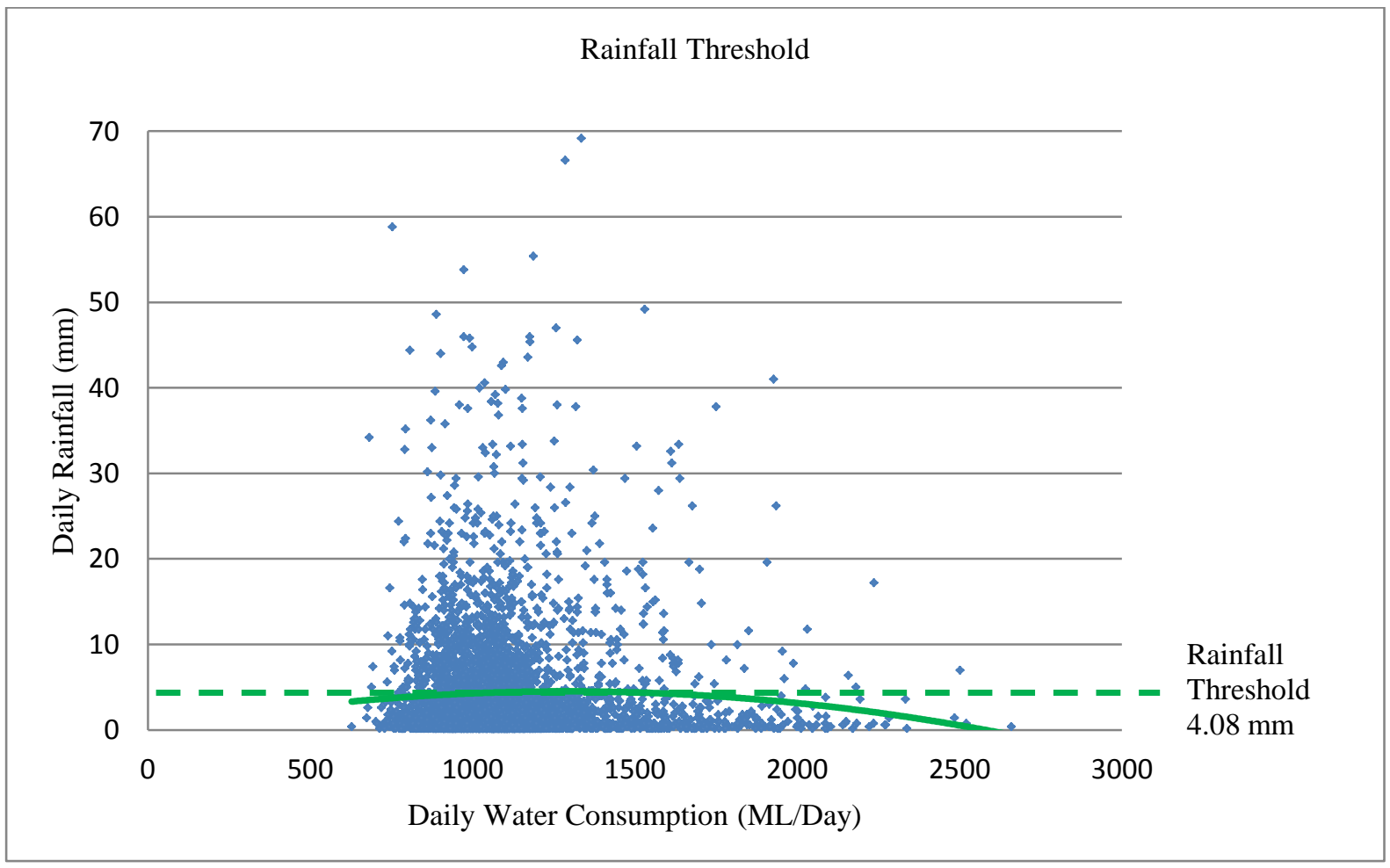

Figure 2. Determination of rainfall thresholds corresponding to water consumption in greater Melbourne.

Previous studies (Gato et al, 2007) showed thresholds of $15.27^{\circ} \mathrm{C}$ and $4.82 \mathrm{~mm}$ for temperature and rainfall for a pure residential area in Melbourne. However, since this study covered the whole Greater Melbourne which is 
not purely residential zone (i.e. residential, industrial, commercial area) thus lower rainfall threshold. In addition, Gato et al. (2007) used quadratic function of reciprocal of daily water use for determining temperature threshold. Interestingly, this study reveals that a polynomial function of reciprocal of daily water consumption could fit better against daily temperature than that of a quadratic function which could be due to type of water consumption (purely residential against mixed zones).

\section{CONCLUSION}

Using dataset of total daily water consumption $(\mathrm{ml} / \mathrm{d})$, daily maximum temperature $\left({ }^{\circ} \mathrm{C}\right)$ and daily rainfall $(\mathrm{mm})$ collected from January 01, 1980 to December 31, 2009, temperature and rainfall thresholds for Greater Melbourne have been identified successfully as $15.53{ }^{\circ} \mathrm{C}$ and $4.08 \mathrm{~mm}$ respectively. It can be concluded that the temperature threshold with respect to mixed water use (i.e. residential, industrial, commercial) is little bit higher than that of purely residential water use. On the other hand, rainfall threshold corresponding to mixed water use (i.e. residential, industrial, commercial) is lower than that of purely residential water use.

The results of this study can be a valuable tool in improving current forecasting urban water demand models which will then be used for assessing water conservation programs.

\section{RECOMMENDATIONS}

From the results of the literature review and analysis of the data, the following recommendations are reached:

1. Adopt the threshold levels determined in developing water demand model for Greater Melbourne and compare results to that of water demand model developed without identified threshold level. This is to confirm previous studies' results that threshold levels significantly improved demand models.

2. Identify threshold levels in other cities in Victoria and in south-eastern part of Australia to develop a general threshold levels in these areas.

\section{ACKNOWLEDGMENTS}

Authors would like to acknowledge to Bureau of Meteorology, Australia for recording temperature and rainfall dataset. Authors are also grateful to Melbourne Water for providing water consumption dataset.

\section{REFERENCES}

Aly, A. H. \& Wanakule, N. (2004). Short-term forecasting for urban water consumption. Journal of Water Resources Planning and Management 130 (5), 405-410.

An, A., Shan, C.C., Cercone, N., Ziarko, W., (1995). Discovering rules from data for water demand prediction. In: Proceedings in the Workshop on Machine Learning and Expert System (IJCAI'95), pp. 187-202.

Arbues, F., Garcia-Valinas, M.A., Martinez-Espineira, R., (2003). Estimation of residential water demand: a estate-of-the-art review. The Journal of Socio-Economics 32, 81-102.

Box, G.E.P., Jenkins, G.M., 1976. Time Series Analysis: Forecasting and Control. Holden-Day, San Francisco, CA.

Campbell, H. E., Johnson, R. M. \& Larson, E. H. (2004). Prices, devices, people, or rules: the relative effectiveness of policy instruments in water conservation. Review of Policy Research 21 (5), 637-662.

Dandy, G., Nguyen, T., Davies, C., (1997). Estimating residential water demand in the presence of free allowances. Land Economics 73 (1), 125-139.

Devore, J.L. (1991). Probability and Statistics for Engineering and Sciences. Duxbury Press, California, USA

Gato, S., N. Jayasuriya, and P. Roberts (2007). Temperature and rainfall thresholds for base use urban water demand modelling, Journal of Hydrology, 337, 364- 376.

Gato, S., N., Jayasuriya, and R. Hadgraft (2003). A simple time series approach to modelling urban water demand, 28th Int. Hydrology and Water Resources Symp., Institution of Engineers, Australia.

Gibbs, K.C., (1978). Price variable in residential demand models. Water Resources Research. 14 (2), $15-18$.

Herrera, M., Torgo, L., Izquierdo, J. \& Pérez-García, R. (2010) Predictive models for forecasting hourly urban water demand. Journal of Hydrology 387 (1-2), 141-150.

Hewitt, J.A., Hanemann, W.M., (1995). A discrete/continuous choice approach to residential water demand under block rate pricing. Land Economics 71 (2), 173-192. 
Howe, C.W., Linaweaver, F.P., (1967). The impact of price on residentialwater demand and its relationship to system design and price structure. Water Resources Research 3 (1), 13-32.

Jacobs, H., and J. Haarhoff (2002). End-use modelling as a means to predict the effects of water demand management, The Biennial Conference of the Water Institute of Southern Africa (WISA), Durban, South Africa. 19 - 23 May 2002

Lyman, R.A., (1992). Peak and off-peak residential water demand. Water Resources Research 28 (9), 2159 2167.

Maidment, D.R., Miaou, S.P., (1986). Daily water use in nine cities. Water Resources Research. 22 (6), 845851.

Maidment, D.R., Miaou, S.P., Crawford, M.M., (1985). Transfer function models of daily urban water use. Water Resources Research. 21 (4), 425-432.

Marshall, A. (1879). Water as an element of national wealth. In: Pigou, A. (Ed.), Memorials of Alfred Marshall. Kelley \& Millman, New York, reprinted in 1956, pp. 134-141.

Miaou, S.P., (1987). Metropolitan's Daily Water Use - Analysis and Forecasting. Technical Report, Metropolitan Water District of Southern California. Los Angeles, CA, USA.

Miaou, S.P., (1990). A class of time-series urban water demand models nonlinear climatic effects. Water Resources Research. 26 (2), 169-178.

Nieswiadomy, M.L., Molina, D.J., (1989). Comparing residential water estimates under decreasing and increasing block rates using household data. Land Economics 65 (3), 280-289.

Taylor B. A. (2012). Predicting monthly domestic water demand from climatic data. Water Science \& Technology: Water Supply. 12.2

Zhou, S.L., McMahon, T.A., Walton, A. and Lewis, J. (2000). Forecasting daily urban water demand: a case study of Melbourne. Journal of Hydrology 236, 153-164.

Zhou, S. L., McMahon, T. A., Walton, A. \& Lewis, J. (2002). Forecasting operational demand for an urban water supply zone. Journal of Hydrology 259 (1-4), 189-202 